\title{
Culture Age on Evaluation of Electrically Active Magnetic Nanoparticles as Accurate and Efficient Microbial Extraction Tools
}

\author{
Barbara C. Cloutier ${ }^{1,2}$, Ashley K. Cloutier², Lorele Trinidad2,3, Evangelyn C. Alocilja ${ }^{2}$ \\ ${ }^{1}$ Large Animal Clinical Sciences, College of Veterinary Medicine, Michigan State University, East Lansing, USA \\ ${ }^{2}$ Department of Biosystems and Agricultural Engineering, Michigan State University, East Lansing, USA \\ ${ }^{3}$ BIOTECH, University of the Philppines Los Baños College, Los Baños, The Philippines \\ Email: barbara.cloutier@us.army.mil, ak.cloutier@yahoo.com, alocilja@msu.edu
}

Received 26 June 2014; revised 23 July 2014; accepted 3 August 2014

Copyright (C) 2014 by authors and Scientific Research Publishing Inc.

This work is licensed under the Creative Commons Attribution International License (CC BY). http://creativecommons.org/licenses/by/4.0/

(c) (7) Open Access

\begin{abstract}
A potential confounding factor in the development and evaluation of biosensors is the diverse nature of the disciplines involved. Biosensor technology involves electrochemistry, microbiology, chemical synthesis, and engineering, among many other disciplines. Biological systems, due to non-homogeneous distribution, are already imprecise compared with other systems, especially food based systems. Inadequate knowledge of the techniques to moderate this leads to ineffective evaluation strategies and potentially halting the pursuit of excellent technology that was merely poorly evaluated. This research was undertaken to evaluate the effect culture age had on the capture efficiency of the electrically active magnetic nanoparticles (EAMNP) using culture as the evaluation tool. The age of culture used for immunomagnetic separation (IMS) over all the experiments was 6 to 18 hours. Ideal culture age range for evaluating biosensors is 4 to 10 hours according to the growth curve for E. coli 0157: $\mathrm{H7}$ in trypticase soy broth. This is supported by the statistically significant difference among organisms in groups from 3 to 10 hours old compared with those grouped from 11 to 18 and $>19$ hours old $(\alpha=0.05, p=0.001$ and $p=0.014$ respectively). The two older categories were not different from each other. The capture efficiency in all biosensor analysis will vary less than when culture of only viable cells is the diagnostic tool. This allows a true evaluation of the consistency and accuracy of the method, less hindered by the variation in the ability to culture the organism.
\end{abstract}

\section{Keywords}

Microorganisms, Culture Age, Nanoparticles, Immunomagnetic Separation, Biosensors 


\section{Introduction}

Immunomagnetic separation (IMS) is a rapid method for extracting and concentrating a target analyte from its sample matrix. This is imperative due to the high level of interference the matrix of a food has on any diagnostic test [1]. IMS has been paired with a wide variety of biosensors for rapid detection of bacterial pathogens [2]-[13]. In IMS, micro- or nano-meter scale magnetic particles are immuno-functionalized with antibody, incubated with the sample to bind target cells, and separated from the sample matrix through application of a magnetic field. The magnetic particle-bound target can then be washed and concentrated removing the matrix interference. The possibility of concentrating target cells prior to detection can eliminate the need for time-consuming pre-enrichment steps with a greater real time analytical sensitivity. In comparison with centrifugation, filtration, or capture of target on an immuno-functionalized surface, the IMS is simpler, and generally results in higher capture efficiency due to the greater surface area available for target binding [2] [14]. This is especially true of nano-sized particles. The surface chemistry of nano-sized particles such as surface tension, magnetization and sheer volume of surface area improves the amount of functionalized space for reaction to occur and thus improves the capture ability and longevity of the resultant IMS particles [2] [14].

The development and evaluation of biosensors are affected by the myriad of disciplines involved in their production. This technology involves components from electrochemistry to engineering [15] [16]. There are few people who are well versed in multiple disciplines. This creates difficulties, for example, when an electrical engineer attempts to produce and challenge a microbiological based biosensor, especially a food based biosensor. Biological systems are imprecise compared with other systems [17]. Although techniques to combat this exist, widespread knowledge of them throughout the diverse disciplines involved in biosensor development is inadequate. This leads to ineffective evaluation and potential rejection of new technologies in the development phase. Theavnot [18] points out that the rapid growth of biosensors has led to "lack of rigor" (p. 2335) in their published performance criteria. Concepts like the $\log _{10}$ conversion of colony forming units per milliliter (CFU/mL) [19], plate counting [20], and most probable number (MPN) calculations [21] are not used consistently in the biosensors literature. International standards for microbiological tests in food exist from the International Standards Organization (ISO) [22]. Organizations like the American Association of Occupational Chemists (AOAC) produce detailed recommendations on analytical expectations of microbiological testing requirements [23]. The field of biosensor technology is improving and expanding every year [16]. Addition of these concepts may allow better evaluation of the existing technology and prevent the discard of valuable diagnostic tools because of lack of rigor in their evaluation.

Antibody based extraction methodology relies on phenotypic recognition of the bacterium. Antibodies cannot differentiate viable cells from non-viable cells and will often perform differently in lag versus log versus stationary growth phases of the bacteria. This can be due to differences in antigen expression during these stages and can be altered by growth conditions and growth media [24]-[27]. While natural contaminations are by nature not controlled, adequate optimization and validation of an extraction methodology and comparison of data from day to day require minimum variation in all parameters except for those being examined. To evaluate a biosensor critically, control over all parameters other than the one under evaluation is a necessity. The objective of the author's body of research is to develop an IMS methodology for food borne pathogens that is analytically sensitive and specific, highly inclusive and exclusive as well as inexpensive. In our initial evaluation of the electrically active magnetic nanoparticles (EAMNPs), the error seen in the capture results was too high to allow evaluations of low levels of contamination [28]. Microbiological culture was used as the verification tool for a positive sample as well as to evaluate the efficiency of the extraction method via capture efficiency calculations. One of the hypothesized reasons for the error seen was the starting culture itself. Since the EAMNPs capture viable and non-viable cells, and the microbiological culture evaluation tool only evaluates viable cells, it seems prudent to examine the start culture for use as early after the log phase of rapid growth and phenotypic change but before a higher percentage of non-viable cells can skew the resultant capture efficiency data. The evaluated IMS technique extracts cells and cell components due to the binding ability of the antibodies to specific bacterial phenotypic proteins that are present in viable or non-viable cells. Culture can only evaluate viable, undamaged cells. Non-viable cells, cells with no chance of capture due to probe overload and cells we have no chance to capture due to changing phenotypic expression in the log phase all add to the variability of the resulting data. The goal was to only use cultures that were out of the rapidly changing log phase of growth, below the known limit of detection of the extraction protocol and mostly viable cells as our challenge solution to limit the variability. In 
order to facilitate this, the following hypothesis was developed and tested.

\section{Experimental Design}

\section{Hypothesis}

The concentration and percentage of non-viable bacterial cells in the start culture results in decreased biosensor capture efficiency estimates as a result of non-growth of non-viable cells on culture media. To test the above hypothesis, detailed growth curves of the chosen strain of E. coli O157:H7, 2006 Japanese Sakai outbreak (Sakai), were developed by recording the time and volume of transfer and an OD600 on each culture. Some of the resultant cultures were IMS extracted with EAMNPs and cultured. Capture efficiencies were calculated to compare categories of culture ages. Matching experiments were performed on the control organisms used in the laboratory.

\section{Materials and Methods}

E. coli $\mathrm{O} 157: \mathrm{H} 7$ strains, E. coli non-H7 strains and non-E. coli bacterial strains were obtained from the STEC Center collection at Michigan State University (MSU) (Shannon Manning, MPH, PhD), the Nano-Biosensors Laboratory at MSU (Evangelyn Alocilja, PhD), Neogen Inc. Research and Development, Lansing, Michigan (Jennifer Rice, DVM, PhD) and the University of Georgia, Center for Food Safety (Dr. Michael Doyle, PhD). From frozen purified culture stocks (stored at $-80^{\circ} \mathrm{C}$ ), colonies were isolated by streak-plate method on trypticase soy agar (BD Biosciences, MD) plates. A single colony was used to inoculate a vial of tryptic soy broth (BD Biosciences, MD) and grown overnight at $37^{\circ} \mathrm{C}$. A $1 \mathrm{~mL}$ aliquot of the liquid culture was transferred to a new vial of broth and stored at $37^{\circ} \mathrm{C}$ for up to 6 days. This culture was used to inoculate a new vial of broth with $1 \mathrm{~mL}$ of inoculum 10 to $24 \mathrm{~h}$ before each experiment to produce fresh bacterial cells which were serially diluted in $0.1 \%(\mathrm{w} / \mathrm{v})$ peptone water (Fluka-Biochemika, Switzerland) prior to their use in the IMS procedure. Varying volumes of stationary broth cultures, colony to broth and freezer stock to broth were inoculated into TSB for the growth curve analysis. Viable cells were enumerated by microbial plating on MacConkey agar with sorbitol (SMAC) (BD Biosciences, MD or Neogen Inc., MI), according to standard rules for plate counting [20]. Optical Density at 600 nanometers (OD600) spectrophotometer readings (BIO-RAD Smartspec 3000, Hercules, CA) were taken from each culture before use as compared to blank Trypticase Soy Broth (TSB). Three readings were taken and averaged together.

\subsection{EAMNP Production}

Ferric chloride hexahydrate (EMD Chemicals, Bedford, MA), sodium acetate (CCI Chemicals, Vernon, CA ), sodium acrylate, sodium chloride $(\mathrm{NaCl})$, ethylene glycol, ethylenediamine, hydrochloric acid, aniline, iron (III) oxide nanopowder, ammonium persulfate, methanol, and diethyl ether were used as received from Sigma Aldrich (St. Louis, MO) in the synthesis of the EAMNPs. EAMNPs were synthesized by polymerization and acid doping of aniline monomer around gamma iron (III) oxide $\left(\gamma-\mathrm{Fe}_{2} \mathrm{O}_{3}\right)$ nano-particles, using a slightly modified published procedure [29]. Briefly, $0.650 \mathrm{~g}$ of iron (III) oxide nanopowder were dispersed in $50 \mathrm{~mL}$ of $1 \mathrm{M} \mathrm{HCl}$, $10 \mathrm{~mL}$ of deionized water and $0.4 \mathrm{~mL}$ of aniline monomer by sonication in an ice bath for 1 hour. A volume of $20 \mathrm{~mL}$ of $0.2 \mathrm{M}$ ammonium persulfate (as oxidant) was added drop-wise to the above solution under continuous magnetic stirring. Color change from rust brown to dark green indicated formation of electrically-active (green) polyaniline over the smaller (brown) $\gamma-\mathrm{Fe}_{2} \mathrm{O}_{3}$ nano-particles. The solution was stirred for 2 hours in an ice bath and was filtered through a qualitative grade filter $(2.5 \mu \mathrm{m}$ pore size, Ahlstrom, grade 601$)$. The supernatant thus obtained was successively filtered through a nitrocellulose membrane filter (1.2 $\mu \mathrm{m}$ pore size, Millipore) followed by washings with $10 \mathrm{~mL}$ each of $1 \mathrm{M} \mathrm{HCl}, 10 \%(\mathrm{v} / \mathrm{v})$ methanol, and diethyl ether. The particles were dried overnight at room temperature under vacuum. The particles ranged in size from 1.2 to $2.5 \mu \mathrm{m}$, and displayed a room temperature saturation magnetization of $30 \mathrm{emu} / \mathrm{g}$.

\subsection{EAMNP Antibody Conjugation}

Nano-particles were immune-functionalized with monoclonal anti-E. coli O157:H7 antibodies obtained from 
Meridian Life Science, Inc. (Saco, ME). Polysorbate-20 (Tween-20), Triton X-100, phosphate buffered saline (PBS), Trizma base, casein, and sodium phosphate (dibasic and monobasic) were used in the IMS procedure. All of the above reagents, unless otherwise noted, were purchased from Sigma-Aldrich (St. Louis, MO). All solutions and buffers used in this study were prepared in de-ionized (DI) water (from Millipore Direct-Q system) as follows: PBS buffer (10 mM PBS, pH 7.4), wash buffer (10 mM PBS, pH 7.4, with $0.05 \%$ Tween-20 or $0.05 \%$ Triton-X100), phosphate buffer (100 mM sodium phosphate, $\mathrm{pH} 7.4)$, blocking buffer (100 mM Tris-HCl buffer, $\mathrm{pH} 7.6$, with $0.01 \% \mathrm{w} / \mathrm{v}$ casein). Magnetic separations were performed with a commercial magnetic separator (Promega Corporation, Madison, WI). Hybridization of biological materials was carried out at room temperature with rotation on a tube rotisserie (Labquake, Thermo Scientific, MA). Scanning electron micrographs were acquired using field-emission scanning electron microscopy (JOEL 7500F, acceleration voltage of $5 \mathrm{kV}$ ). A superconducting quantum interference device magnetometer (Quantum design MPMS SQUID) was used for magnetic characterization of EAMNPs.

Mab-conjugation of the EAMNPs was carried out by physical adsorption of antibodies onto the polyaniline surface. Electrostatic interactions between the negatively charged constant $(\mathrm{Fc})$ portion of the antibodies and the positively charged polyaniline surface are thought to play a role in adsorption and orientation of the biomolecules onto the EAMNPs [30]. Successful conjugation of antibodies onto EAMNPs was confirmed by measuring the quantity of antibody in the post-hybridization supernatant with a commercial fluorescence-based protein quantification kit. The measured protein concentration in the supernatant was significantly lower than the concentration of antibodies initially added to the MNPs (data not shown), indicating that antibodies were retained on the MNPs during hybridization. EAMNPs were conjugated with monoclonal antibodies at an initial EAMNP concentration of $10 \mathrm{mg} / \mathrm{mL}$ ( $1 \%$ solid). A $100 \mu \mathrm{L}$ aliquot of monoclonal, anti-E. coli O157:H7 antibody (suspended in $0.1 \mathrm{M}$ phosphate buffer) was added to EAMNPs suspended in PBS, yielding a final antibody concentration of $1.0 \mathrm{mg} / \mathrm{mL}$. The mixture was hybridized on a rotisserie-style rotator for 1 hour at room temperature, with $25 \mu \mathrm{L}$ of $10 \mathrm{X}$ PBS being added after the first $5 \mathrm{~min}$ of hybridization, to increase the sodium chloride content of the suspension to approximately $0.14 \mathrm{M}$. Following hybridization, the EAMNP-antibody conjugate was magnetically separated, the supernatant removed, and the conjugate re-suspended in $250 \mu \mathrm{L}$ of blocking buffer $(0.1 \mathrm{M}$ tris buffer with $0.01 \%$ casein) for $5 \mathrm{~min}$. Again the conjugate was magnetically separated, the supernatant removed, and the conjugate re-suspended in $250 \mu \mathrm{L}$ of blocking buffer, this time for 1 hour with rotation. Finally, the EAMNP-antibody conjugate was magnetically separated, the supernatant removed, and the conjugate re-suspended in $2.5 \mathrm{~mL}$ of $0.1 \mathrm{M}$ phosphate buffered saline (PBS). The final concentration of EAMNPs in each solution was $1.0 \mathrm{mg} / \mathrm{mL}$. Immuno-conjugated EAMNPs (Mab-EAMNPs) were stored at $4^{\circ} \mathrm{C}$. Prior to experimental use, Mab-EAMNPs were or further diluted in $0.1 \mathrm{M}$ PBS, in order to obtain solutions at $0.5 \mathrm{mg} / \mathrm{mL}$ EAMNPs.Avoid combining SI and CGS units, such as current in amperes and magnetic field in oersteds. This often leads to confusion because equations do not balance dimensionally. If you must use mixed units, clearly state the units for each quantity that you use in an equation.

\subsection{Immuno-Magnetic Separation (IMS) and Plating of Bacteria}

Every experiment was applied to three different bacterial species individually: E. coli O157:H7 Sakai strain, $E$. coli O157:H7 2006 Spinach strain, pGFPuv (target species), Shigella boydii (non-target species). S. boydii bears less genotypic and phenotypic similarity to the target organism, but it is a commonly encountered food borne pathogen, and also produces shiga-toxin like E. coli $\mathrm{O} 157: \mathrm{H} 7$. The standard positive control used was $E$. coli O157:H7 2006 Spinach strain, pGFPuv. Its ability to fluoresce green in the presence of UV light provided confirmation that the positive samples were not cross contaminated from the positive control. The non-target organisms chosen for this study correspond with the recommendations made by the AOAC Task Force on Best Practices in Microbiological Methodology [23]. Serial dilutions of each bacterium were independently prepared in $0.1 \%(\mathrm{w} / \mathrm{v})$ peptone water, along with subsequent negative, positive and blank controls. Three or four of the pure dilutions of each bacteria were plated (100-mL aliquots) on sorbitol Mac Conkey agar (SMAC) and incubated at $37^{\circ} \mathrm{C}$ overnight. For IMS, $50 \mathrm{~mL}$ of Mab-EAMNPs and $50 \mathrm{~mL}$ of the appropriate bacterial dilution were combined with $400 \mathrm{~mL}$ of $0.01 \mathrm{M}$ PBS (pH 7.4), and hybridized with rotation at room temperature for $30 \mathrm{mi}-$ nutes.After hybridization, the cell-Mab-EAMNP complexes were magnetically separated and the supernatant removed. Complexes were washed twice in wash buffer (0.01 M PBS containing $0.05 \%$ Triton-X100), and finally re-suspended in $0.5 \mathrm{~mL}$ of $0.01 \mathrm{M}$ PBS. The IMS procedure required $40 \mathrm{~min}$, and is depicted in Figure 1. 


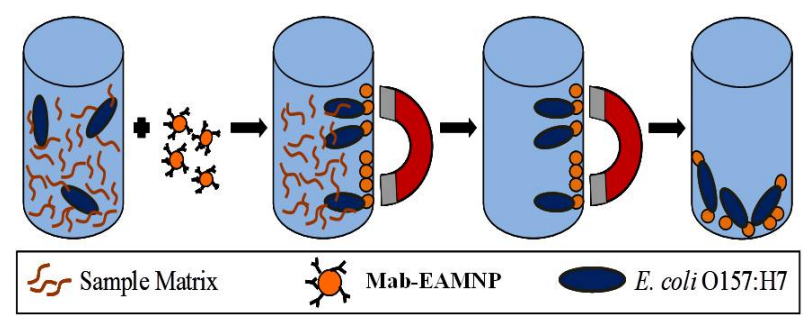

Figure 1. Immuno-magnetic separation procedure (IMS): sample plus Mab-EAMNPs $\rightarrow$ magnetic separation of target cells $\rightarrow$ removal of sample matrix $\rightarrow$ purified E. coli $\mathrm{O} 157: \mathrm{H} 7-\mathrm{Mab}-$ EAMNP complexes.

A $100-\mathrm{mL}$ aliquot was placed on SMAC and incubated at $37^{\circ} \mathrm{C}$ overnight. The number of colony-forming units (CFU) in the 100-mL aliquot was determined by manually counting the colonies on each plate. For every experimental case (i.e., particular combination of Mab-EAMNP concentration, and bacteria), a minimum of two bacterial dilutions underwent IMS and were plated. In most cases a full spectrum of dilutions from $10^{-1}$ to $10^{-9}$ were run as independent units. For the lower dilutions from $10^{-1}$ to $10^{-5}$ the final IMS solution was diluted from 5 to 1 time respectively to obtain countable plates. For dilutions from the $10^{-8}$ and $10^{-9}$ series, all $500 \mu \mathrm{L}$ present were plated.

Calculation of bacterial cell concentrations in both pure and IMS separated samples were carried out according to rules provided by the United States Food and Drug Administration's Bacteriological Analytical Manual [20]. In addition, separate runs were performed where the final IMS solution was all plated to determine if any cells were collected at all, instead of the standard $100 \mu \mathrm{L}$. The CFU/mL calculations were adjusted accordingly to accommodate the change in plated dilution factor.

Capture efficiency as defined by the amount captured divided by the amount present in the original sample was calculated for each sample at each concentration for E. coli $\mathrm{O} 157: \mathrm{H} 7$, and each negative and positive control. Capture efficiency was calculated by conversion of CFU/mL to $\log _{10} \mathrm{CFU} / \mathrm{mL}$ when above $10 \mathrm{CFU} / \mathrm{mL}$. The $\log _{10}$ conversion also normalizes the distribution [19]. When calculating capture efficiency at the lower concentrations the log transformation is not performed since with a base 10 the result would be zero. Actual $\mathrm{CFU} / \mathrm{mL}$ was used in this range to calculate capture efficiency.

\subsection{Statistical Analysis}

Statistical analysis was performed using SPSS software (Armonk, NY). Data was collected by hour and the resultant capture efficiencies grouped into categories of $3-10$ hours, $11-18$ hours and $19-24$ hours. Subsequent analysis was performed using one way anova evaluation with a post hoc comparison using dunnet's t-tests using the $3-10$ hour category as the control to evaluate the effect of age on Mab-EAMNP extraction. All analyses were calculated with $95 \%$ confidence intervals $(\alpha=0.05)$.

\section{Results}

Accurate growth curves for the bacterial strains we were using were developed under our laboratory conditions and equipment. Cumulative data from all extraction runs done over an 8 month period were tabulated and separated by time in hours and by inoculation volume. Figure 2 shows the resultant growth curve for E. coli O157:H7 Sakai strain, for a $1 \mathrm{~mL}$ transfer aliquot. Identical curves for other inoculums of $E$. coli O157:H7 and all growth curves for E. coli $\mathrm{O} 55: \mathrm{H} 7$ and Shigella boydii are available in supplementary data or on request.

\section{Discussion}

As our attempts to hold the cell culture constant were continuing while data was being collected, the data in this report represents data generated with differing culture conditions, ages and concentrations of viable and nonviable cells. The primary age of culture used for IMS over all the experiments was 6 to 18 hours old. Ideal time frames for the age of the culture are from 4 to 10 hours according the growth curve for a $1 \mathrm{~mL}$ in to $10 \mathrm{~mL}$ 
E. coli 0157:H7 Sakai strain, Growth Chart 1 mL Transfer

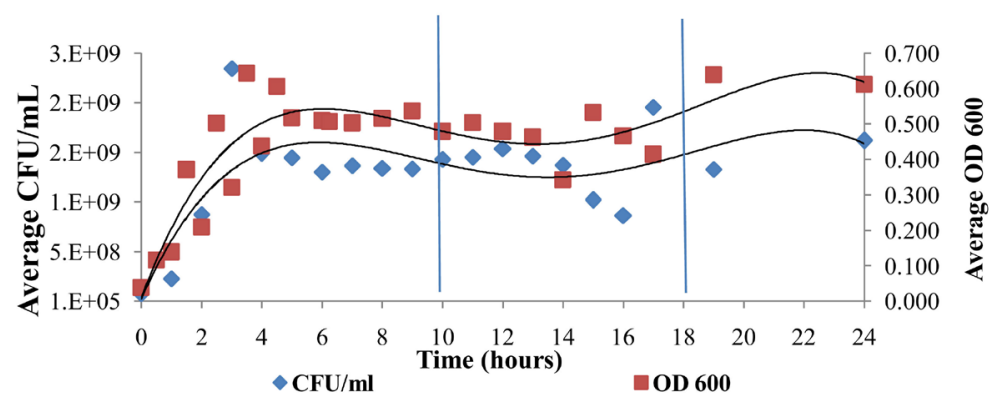

Figure 2. E. coli O157:H7 Sakai strain growth by hour of a $1 \mathrm{~mL}$ inoculum into $10 \mathrm{~mL}$ TSB.

inoculums. This is supported by the increase in capture efficiency by the same biosensor with different ages of cultures shown in Figure 3. This is supported by the statistically significant difference between organisms blocked from 3 - 10 hours old and those blocked from 11 to 18 and $>19$ hours old, shown in Figure 4 . The two older categories were no different from each other. The capture efficiency in all biosensor analysis will vary less then when known challenge concentrations lead to inaccurate classification on the electrochemical platform and a perceived variability of results by concentration of bacterial cells. Since one of the goals of effective biosensor evaluation is to evaluate the range and differentiation of the linear range results by cell concentrations, this could make a difference in the decision to move a biosensor from concept to validation studies [18]. Inaccurate known challenge concentrations add to the variability we see in the data for biosensors we create in the author's laboratory. The OD600 spectrophotometer evaluations as compared to the cultured CFU/mL and the age of the inoculums assist in both explaining early data variation and facilitate decisions on logistics for future data collection.

\section{Conclusions and Limitations}

This cumulative total of 323 repetitive broth challenges yielded statistically significant extraction and culture detection by capture efficiency. Monitoring the age of the inoculating culture during initial challenges of the EAMNP IMS methodology will allow future studies to better control the unintentional error not related to technology under evaluation. When culture is used as the gold standard, test sensitivity calculations will be depressed due to increasing the false negative fractions on those with non-viable or viable and non-culturable bacteria in the system. Test sensitivity calculations are already a problem in the range of bacterial concentrations that are below the culture limit of detection, around $100 \mathrm{CFU} / \mathrm{mL}$ [23]. This is mostly due to the non-homogenous nature of bacteria in solution. The probability of pipeting the exact fraction the few bacteria reside in decreases as the culture becomes more dilute, increasing the degree of error.

Limitations of this extraction method include the fact that both viable and non-viable cells are extracted with this methodology. Further studies are designed and being implemented to evaluate the Mab-EAMNP to determine the reaction kinetics of non-viable verses viable cells on the antibody target region in broth cultures. Limits of detection, inclusivity and exclusivity of microbial families and biosensor platform experiments are necessary before validation trials of the whole biosensor can proceed. The ultimate goal of this culture age evaluation is to be able to capture only viable cells when the diagnostic evaluation is by culture. This allows a true evaluation of the consistency and accuracy of the method, less hindered by the variation in the ability to culture the organism. This also has ramifications on the electrochemistry results of a biosensor. Future multiplexing with multiple EAMNP and multiple bacterial targets could have interactions between the EAMNPs or between the mixed antibodies. Certain matrices may remove the Mab from the surface of the EAMNPs and make their use in that matrix impossible. For field based diagnostics, the largest drawback of this method is the need for refrigeration of the Mab-EAMNPs. When field based technologies are discussed, shelf stable reagents are an advantage.

\section{Acknowledgements}

This work was funded in part by the US Department of Homeland Security through the National Center for 


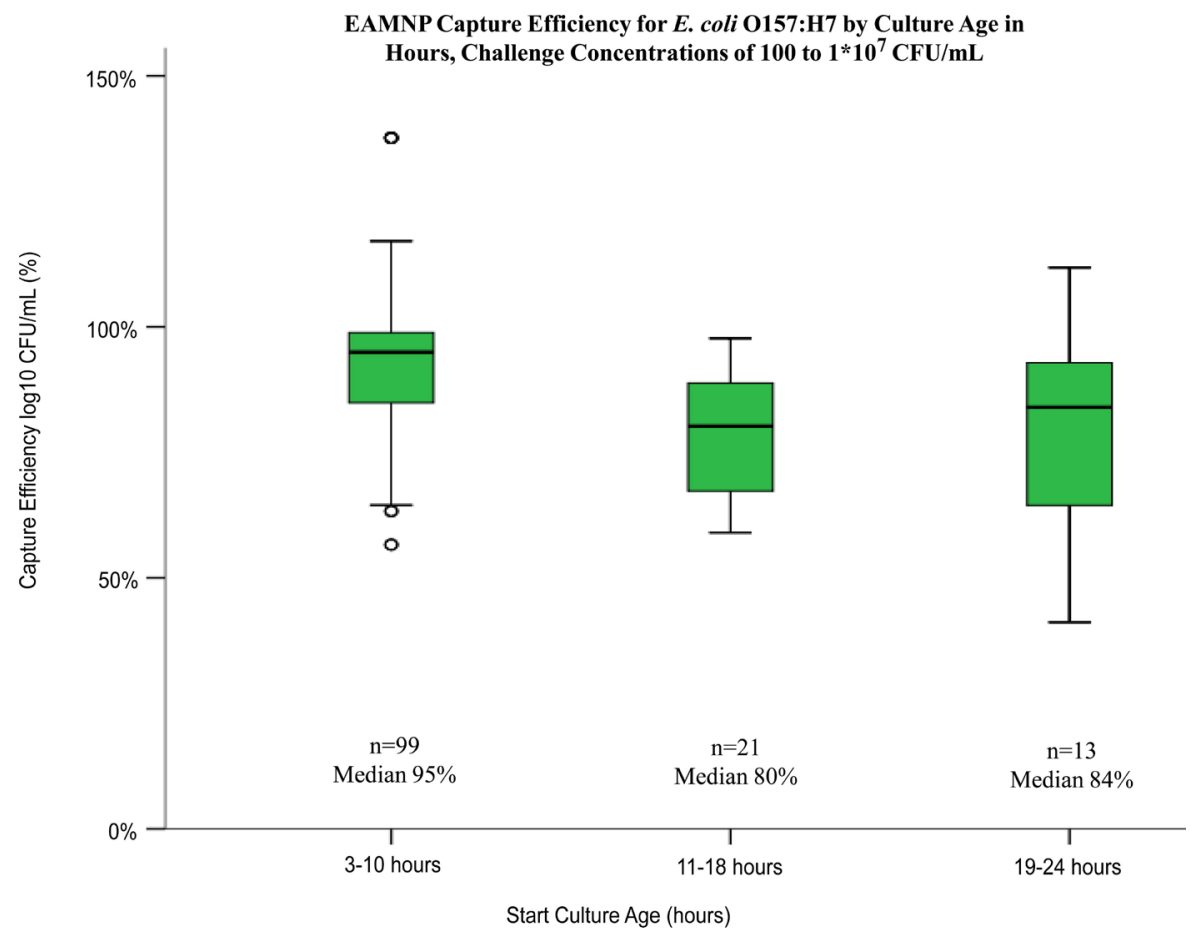

Figure 3. E. coli O157:H7, Sakai strain, capture efficiency comparison by age of start culture. Statistical comparisons were made between groups and are shown in Figure 4.

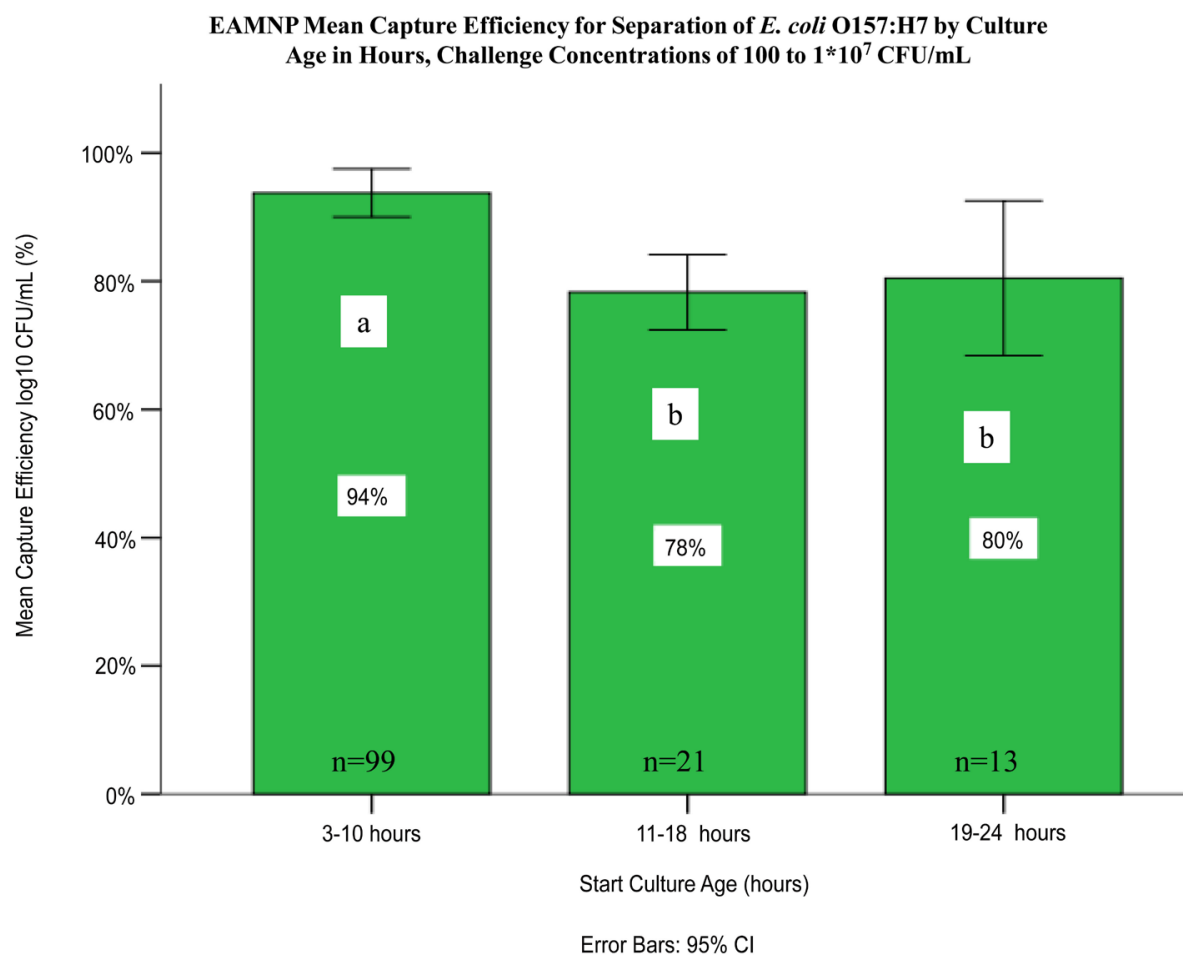

Figure 4. E. coli O157:H7, Sakai strain, mean capture efficiency comparison by age of start culture. Statistical comparisons were made between groups as a one way anova with a one tailed Dunnet's t-test. Groups were labeled (b) if they were statistically less than groups labeled (a). ( $3-10$ hours vs. $11-18$ hours, $p=0.001 ; 3-10$ hours vs. $19-24$ hours, $p=0.014 ; \alpha=0.05$ ). 
Food Protection and Defense under Grant R9106007101, and in part by the US Environmental Protection Agency through award number RD83300501. These funding sources had no involvement in the actual research or writing of this report. The contents of this publication do not necessarily reflect the position or policy of the Federal Government.

The authors would like to thank Dr. Stanley Flegler and Carol Flegler for assistance with SEM studies, Dr. Reza Loloee for assistance with magnetism measurements, Dr. Paul Bartlett and the MSU Center for Statistical Training and Consulting (CSTAT) for assistance with statistical analyses, Dr. Julie Funk and Dr. Shannon Manning for providing bacterial cultures and for advice on microbiological methods, and Dr. John Linz and Dr. Elliot Ryser for offering information on best practices in food microbiology.

\section{References}

[1] Ge, B. and Meng, J. (2009) Advanced Technologies for Pathogen and Toxin Detection in Foods: Current Applications and Future Directions. Journal of the Association for Laboratory Automation, 14, 235-241. http://dx.doi.org/10.1016/j.jala.2008.12.012

[2] Cheng, Y., Liu, Y., Huang, J., Li, K., Zhang, W., Xian, Y. and Jin, L. (2009) Nanoscale Assembly of Amine-Functionalized Colloidal Iron Oxide. Journal of Magnetism and Magnetic Materials, 321, 1529-1532. http://dx.doi.org/10.1016/j.jmmm.2009.02.080

[3] Gehring, A.G. and Tu, S.I. (2005) Enzyme-Linked Immune-Magnetic Electrochemical Detection of Live Escherichia coli O157:H7 in Apple Juice. Journal of Food Protection, 68, 146-149.

[4] Gehring, A.G., Brewster, J.D., Irwin, P.L., Tu, S.I. and VanHouten, L.J. (1999) 1-Naphthylphosphate as an Enzymatic Substrate for Enzyme-Linked Immune-Magnetic Electrochemistry. Journal of Electroanalytical Chemistry, 469, 27-33. http://dx.doi.org/10.1016/S0022-0728(99)00183-7

[5] Jaffrezic-Renault, N., Martelett, C., Chevolot, Y. and Cloarec, J.P. (2007) Biosensors and Biobarcode Assays Based on Biofunctionalized Magnetic Microbeads. Sensors, 7, 589-614. http://dx.doi.org/10.3390/s7040589

[6] Maalouf, R., Hassen, W., Fournier-Wirth, C., Coste, J. and Jaffrezic-Renault, N. (2008) Comparison of Two Innovatives Approaches for Bacterial Detection: Paramagnetic Nanoparticles and Self-Assembled Multilayer Processes. Microchimica Acta, 163, 157-161. http://dx.doi.org/10.1007/s00604-008-0008-3

[7] Perez, F.G., Mascini, M., Tothill, I.E. and Turner, A.P.F. (1998) Immuno-Magnetic Separation with Mediated Flow Injection Analysis Amperometric Detection of Viable Escherichia coli O157. Analytical Chemistry, 70, 2380-2386. http://dx.doi.org/10.1021/ac970715t

[8] Ruan, C., Wang, H. and Li, Y. (2002) A Bioenzyme Electrochemical Biosensor Coupled with Immuno-Magnetic Separation for Rapid Detection of Escherichia coli O157:H7 in Food Samples. Transactions of the ASAE, 45, 249-255. http://dx.doi.org/10.13031/2013.7853

[9] Tu, S.I., Golden, M., Cooke, P., Paoli, G. and Gehring, A. (2005) Detection of Escherichia coli O157:H7 through the Formation of Sandwiched Complexes with Immuno-Magnetic and Fluorescent Beads. Journal of Rapid Methods \& Automation in Microbiology, 13, 269-282. http://dx.doi.org/10.1111/j.1745-4581.2005.00026.x

[10] Varshney, M. and Li, Y. (2007) Interdigitated Array Microelectrode Based Impedance Biosensor Coupled with Magnetic Nanoparticles-Antibody Conjugates for Detection of Escherichia coli O157:H7 in Food Samples. Biosensors and Bioelectronics, 22, 2408-2414. http://dx.doi.org/10.1016/j.bios.2006.08.030

[11] Varshney, M., Li, Y., Srinivasan, B. and Tung, S. (2007) A Label-Free, Microfluidics and Interdigitated Array Microelectrode-Based Impedance Biosensor in Combination with Nanoparticles Immunoseparation for Detection of Escherichia coli O157:H7 in Food Samples. Sensors and Actuators B: Chemical, 128, 99-107. http://dx.doi.org/10.1016/j.snb.2007.03.045

[12] Varshney, M., Yang, L., Su, X.L. and Li, Y. (2005) Magnetic Nanoparticles-Antibody Conjugates for the Separation of Escherichia coli O157:H7 in Ground Beef. Journal of Food Protection, 68, 1804-1811.

[13] Yang, L. and Li, Y. (2006) Detection of Viable Salmonella Using Microelectrode-Based Capacitance Measurement Coupled with Immunomagnetic Separation. Journal of Microbiological Methods, 64, 9-16. http://dx.doi.org/10.1016/j.mimet.2005.04.022

[14] Jiang, X., Wang, R., Wang, Y., Su, X., Ying, Y., Wang, J. and Li, Y. (2011) Evaluation of Different Micro/Nanobeads Used as Amplifiers in QCM Immunosensor for More Sensitive Detection of E. coli O157:H7. Biosensors and Bioelectronics, 29, 23-28. http://dx.doi.org/10.1016/j.bios.2011.07.059

[15] Nayak, M., Kotian, A., Marathe, S. and Chakravortty, D. (2009) Detection of Microorganisms Using Biosensors: A Smarter Way towards Detection Techniques. Biosensors and Bioelectronics, 25, 661-667. http://dx.doi.org/10.1016/j.bios.2009.08.037 
[16] Lazcka, O., Del Campo, F.J. and Muñoz, F.X. (2007) Pathogen Detection: A Perspective of Traditional Methods and Biosensors. Biosensors and Bioelectronics, 22, 1205-1217. http://dx.doi.org/10.1016/j.bios.2006.06.036

[17] Adams, M.R. and Moss, M.O. (2008) Food Microbiology. 3rd Edition, RSC Publishing, Cambridge.

[18] Theavnot, D.R., Toth, K., Durst, R.A. and Wilson, G.S. (1999) Electrochemical Biosensors: Recommended Definitions and Classification. Pure Applied Chemistry, 71, 2333-2348.

[19] Mettler, D. and Tholen, D. (2007) G108 - Guidelines for Estimating Uncertainty for Microbiological Counting Methods. http://www.a2la.org/guidance/MU for_Micro_Labs.pdf

[20] FDA (2009) Bacteriological Analytical Manual (BAM). US Food \& Drug Administration, Silver Springs, MD, USA.

[21] USDA FSIS (2010) Microbiology Laboratory Guidebook. http://www.fsis.usda.gov/science/microbiological_lab_guidebook/

[22] ISO Website (2011) http://www.iso.org/iso/home.html

[23] AOAC (2006) Final Report and Executive Summaries from the AOAC International Presidential Task Force on Best Practices in Microbiological Methodology. AOAC International, Rockville.

[24] Blackburn, C. and McCarthy, J.D. (2000) Modifications to Methods for the Enumeration and Detection of Injured Escherichia coli O157:H7 in Foods. International Journal of Food Microbiology, 55, 285-290. http://dx.doi.org/10.1016/S0168-1605(00)00205-1

[25] Durso, L.M. and Keen, J.E. (2007) Shiga-Toxigenic Escherichia coli O157 and Non-Shiga-Toxigenic E. coli O157 Respond Differently to Culture and Isolation from Naturally Contaminated Bovine Faeces. Journal of Applied Microbiology, 103, 2457-2464. http://dx.doi.org/10.1111/j.1365-2672.2007.03473.x

[26] Fitzmaurice, J., Duffy, G., Kilbride, B., Sheridan, J.J., Carroll, C. and Maher, M. (2004) Comparison of a Membrane Surface Adhesion Recovery Method with an IMS Method for Use in a Polymerase Chain Reaction Method to Detect Escherichia coli O157:H7 in Minced Beef. Journal of Microbiological Methods, 59, 243-252. http://dx.doi.org/10.1016/j.mimet.2004.07.007

[27] Fung, D. (2008) Rapid Methods and Automation in Food Microbiology: 25 Years of Development and Predictions. In: Barbosa-Cánovas, G.V., Mortimer, A., Lineback, D., Spiess, W. and Buckle, K., Eds., IUFoST World Congress Book: Global Issues in Food Science and Technology, Academic Press, Waltham.

[28] Setterington, E., Cloutier, B., Ochoa, J., Cloutier, A. and Alocilja, E. (2011) Rapid, Sensitive, and Specific Immunomagnetic Separation of Food Borne Pathogens. International Journal of Food Safety, Nutrition and Public Health, 4, 83-100. http://dx.doi.org/10.1504/IJFSNPH.2011.042576

[29] Pal, S., Setterington, E.B. and Alocilja, E.C. (2008) Electrically Active Magnetic Nanoparticles for Concentrating and Detecting Bacillus anthracis Spores in a Direct-Charge Transfer Biosensor. IEEE Sensors Journal, 8, 647-654. http://dx.doi.org/10.1109/JSEN.2008.922687

[30] Pal, S. and Alocilja, E.C. (2009) Electrically Active Polyaniline Coated Magnetic (EAPM) Nanoparticles as Novel Transducer in Biosensor for Detection of Bacillus anthracis Spores in Food Samples. Biosensors and Bioelectronics, 24, 1437-1444. http://dx.doi.org/10.1016/j.bios.2008.08.020 
Scientific Research Publishing (SCIRP) is one of the largest Open Access journal publishers. It is currently publishing more than 200 open access, online, peer-reviewed journals covering a wide range of academic disciplines. SCIRP serves the worldwide academic communities and contributes to the progress and application of science with its publication.

Other selected journals from SCIRP are listed as below. Submit your manuscript to us via either submit@scirp.org or Online Submission Portal.
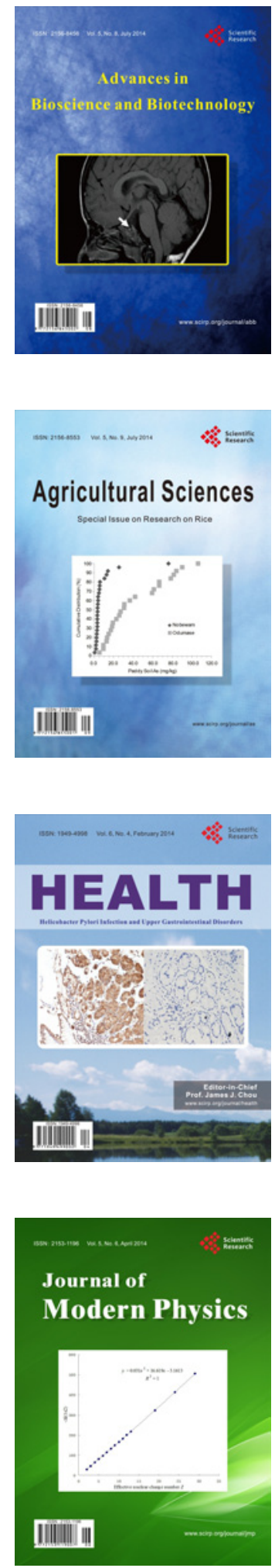
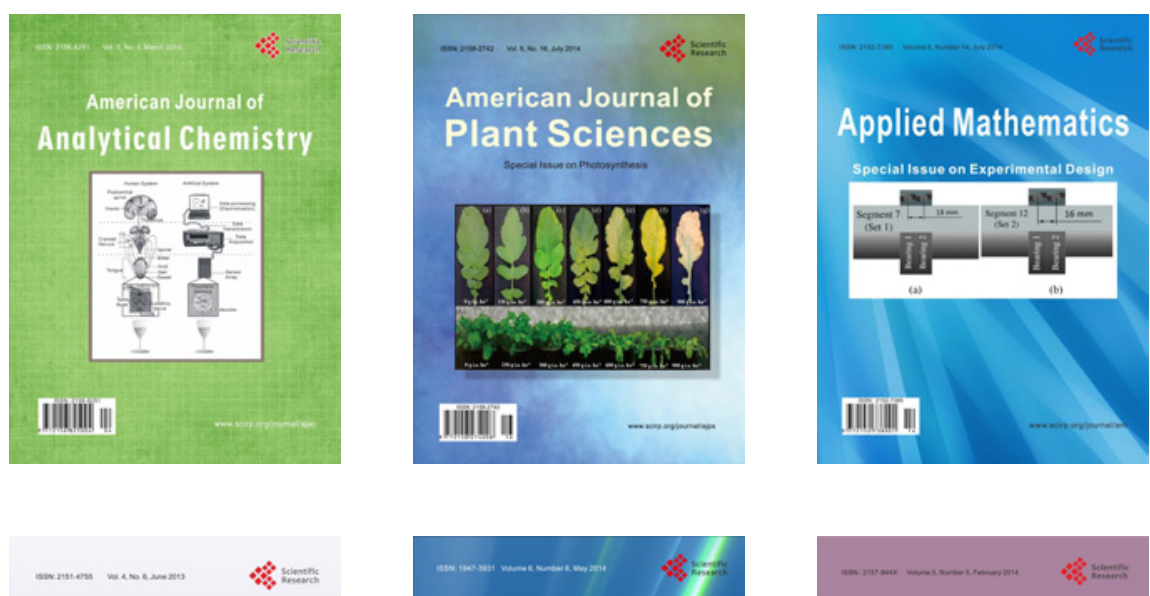

Creative Education
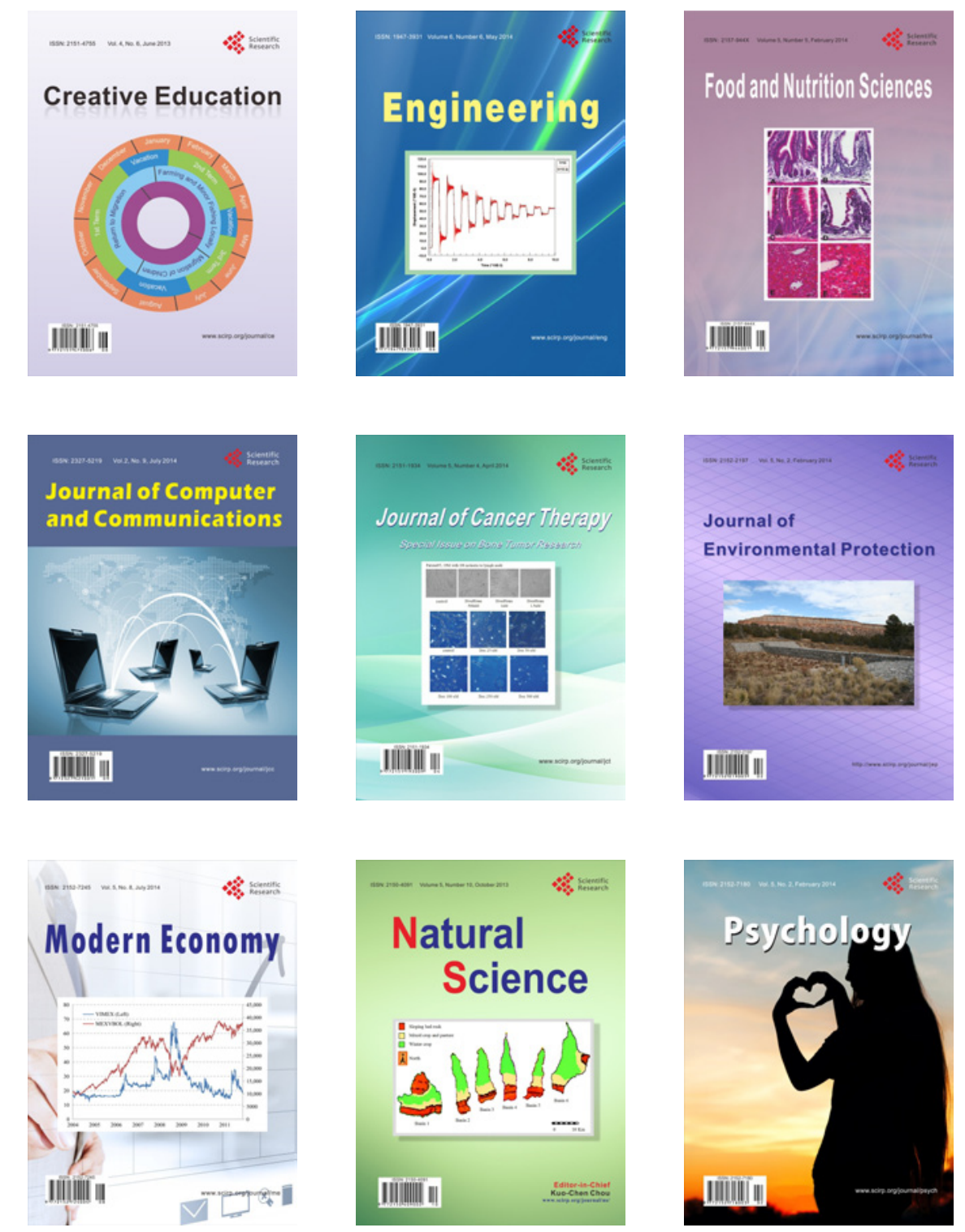